\title{
INTRAMEDULLARY SPINAL CORD AND CAUDA EQUINA METASTASIS OF BREAST CARCINOMA: CASE REPORT
}

\author{
Lumir Hrabalek*a, Ondrej Kalita ${ }^{\text {a }}$ Hana Studentova ${ }^{\mathrm{b}}$, Jana Jankovac ${ }^{\mathrm{c}}$ Jiri Ehrmann ${ }^{\mathrm{c}}$, \\ Radek Trojanec ${ }^{\mathrm{d}}$, Marian Hajduch ${ }^{\mathrm{d}}$ \\ a Department of Neurosurgery, Palacky University and University Hospital Olomouc, Czech Republic \\ b Department of Oncology, Palacky University and University Hospital \\ c Department of Pathology, Laboratory of Molecular Pathology, Faculty of Medicine and Dentistry, Palacky University \\ and University Hospital \\ d Laboratory of Experimental Medicine, Department of Pediatrics, Palacky University and University Hospital \\ E-mail:lumir.hrabalek@seznam.cz
}

Received: November 2, 2009; Accepted: April 1, 2010

Key words: Intramedullary/Spinal cord/Metastasis/Breast cancer/Surgery/Leptomeningeal disease

Aim. We present a case report of a female patient with metastasis of breast carcinoma to the medullary conus and cauda equina.

Methods. A 48-year-old woman with a history of breast tumor, suddenly felt severe weakness and numbness of the lower extremities. MRI of the spine disclosed a mass lesion within the medullary conus, with leptomeningeal involvement of cauda equina at the spinal level L1. Laminectomy was performed and partial resection of the medullary conus tumor and especially release of nerve roots of cauda equina was achieved using microsurgical techniques.

Results. Her clinical status, especially right leg weakness and sensory loss in the lower extremities have immediately improved but bladder dysfunction remained and she was unable to walk.

The histological picture and immunophenotype indicates the presence of metastatic ductal adenocarcinoma of the mammary gland. Patient died 4 months after the spinal cord and cauda equina surgery.

Conclusion. To our knowledge, this is the first report of successful surgical treatment of metastatic leptomeningeal infiltration of breast carcinoma.

\section{INTRODUCTION}

Intramedullary spinal cord metastases (ISCM) are rare. ISCM clinically affects only $0.1-0.4 \%$ of all cancer patients $^{1-3}$. Most patients with ISCM present with rapid progressive neurological deficits and require immediate examination ${ }^{1,2,4-6}$. Currently, spinal magnetic resonance imaging (MRI) is applied routinely for the diagnosis of ISCM $^{3,7-11}$. Surgery aims at decompression of functional neural tissue and histological confirmation of the tumor ${ }^{6}$. As with other central nervous system (CNS) metastases, patients with ISCM have a very short life expectancy, with a median survival of 3 to 4 months from the time of diagnosis $^{3,4,12}$. In this paper we present one case of surgically treated ISCM.

\section{CASE REPORT}

A 41-year-old premenopausal woman was presented with a locally advanced tumor of the left breast T4N1M0 (stage III) in February 2001. Histopathological examination of breast tumor and left axillary lymph node revealed an infiltrating ductal carcinoma grade III. Tumor was Her-2/neu negative, estrogen and progesterone receptor positive in $90 \%$ and $60 \%$ of tumor cells respectively. The patient was treated with neoadjuvant chemotherapy (do- cetaxel and epirubicin). She achieved complete response and was then followed-up on a regular basis. In August 2007, she was diagnosed with reccurence of the tumor in the left breast and contralateral axillary lymph nodes. She started hormonal therapy (Arimidex) and underwent bilateral mastectomy and bilateral axillary lymph node dissection followed by adjuvant chemotherapy (doxorubicin, cyclophosphamide and paclitaxel) and radiotherapy (50 Gy). However, the patient suddenly felt severe weakness, paresthesia and numbness of the lower extremities and she was unable to walk in August 2008. Urinary incontinence developed over the following 7 days. MRI of the lumbar spine disclosed a $2 \times 1 \mathrm{~cm}$ mass lesion within the medullary conus, probably with leptomeningeal involvement of the spinal cord and cauda equina at spinal level L1. The lesion was isointense in T1 and T2 - weighted sequences and had significant enhancement after gadolinium based contrast agent injection. No bone destruction or epidural tumor was seen (Fig. 1). Cranial, cervical and thoracic MRI examinations did not reveal any further metastases. Whole body PET/CT (Positron Emission Tomography / Computed Tomography) confirmed only tumor of the spinal canal at level L1. As the MRI and PET/CT findings suggested isolated tumor (dif. dg. ependymoma, astrocytoma, metastasis or others) and the physical condition of the patient was appropriate, surgery was indicated. This was performed ten days after 
clinical presentation. Laminectomy L1 and durotomy were performed and a medullary conus tumor with leptomeningeal infiltration of medullary conus and cauda equina was found. The medullary conus was significantly enlarged and the nerve roots of cauda equina were pasted together by leptomeningeal infiltration. Partial resection of the medullary conus tumor and especially release of the nerve roots of the cauda equina was achieved using an operating microscope and microsurgical techniques. The patient did not experience notable complications related to surgery. Her clinical status, especially right leg weakness and sensory loss in the lower extremities immediately improved but bladder dysfunction remained and she was still unable to walk.

\section{Histological and Genetic Findings}

Microscopic examination. Fragmented nervous tissue infiltrated with structures of adenocarcinoma partially arranged in trabecules, focally in tubules.

Immunophenotype of tumor cells. Positivity of cytokeratin AE1-AE3, cytokeratin 7 and estrogen receptor (Fig. 2); Negativity of progesterone receptor, vimentin and S100 protein; Proliferative activity (nuclear Ki-67 expression) 10-20\%; Histological picture and immunophenotype indicates presence of metastatic ductal adenocarcinoma of mammary gland; Cytogenetic analysis of the tumor was performed using fluorescence in situ hybridisation (FISH): However, it did not show the numeric abberration of genes or chromosomes frequently involved in breast cancer pathology: Her-2/neu, TOP2A, RB1, p53, C-MYC, cyclin D1, chromosomes 8,11 or 17.

Postoperatively she underwent spinal local radiotherapy (30 Gy) but her neurological deficit did not further improve. Her general condition deteriorated. Two months after surgery, she was not able to swallow and an MRI of the brain revealed only leptomeningeal infiltration of the left facial nerve. MRI of spinal canal was not indicated. The patient died in January 2009, 4 months after the spinal cord and cauda equina surgery.

\section{DISCUSSION}

Technically, ISCM without leptomeningeal involvement is idealy suited for surgery. ISCM can be removed safely in many cases, since most ISCM are well encapsulated and some are cystic. Cystic tumors often lend themselves to surgical extirpation because the cystic component often reaches the surface of the cord and can therefore be more easily removed without disruption to normal structures ${ }^{13}$. In case of leptomeningeal involvement, radical excision is impossible and it is preferred to limit removal to the well-defined portion of the tumor ${ }^{14}$. Dam-Hieu et al. ${ }^{14}$ reported one case of successful surgical treatment of leptomeningeal infiltration of medullary conus and cauda equina and our paper reports the second case. It suggests the possibility of neurological improve-

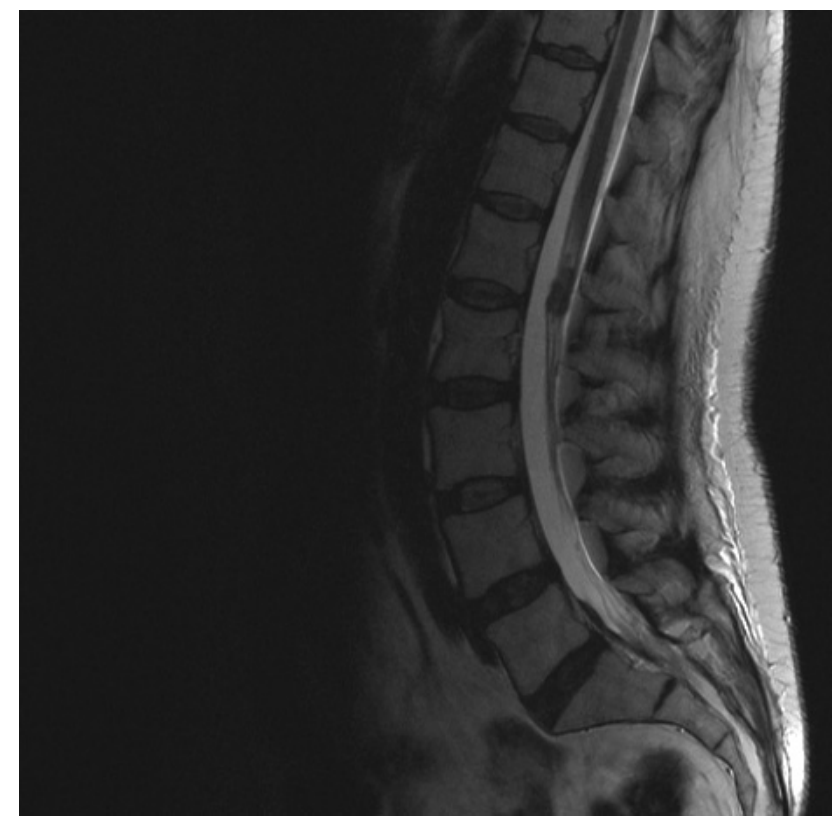

Fig. 1. Sagital T1-weighted MRI of the lumbar spine disclosed a 2 x $1 \mathrm{~cm}$ isointense mass lesion within the medullary conus, probably with leptomeningeal involvement of the spinal cord and cauda equina at spinal level L1 .

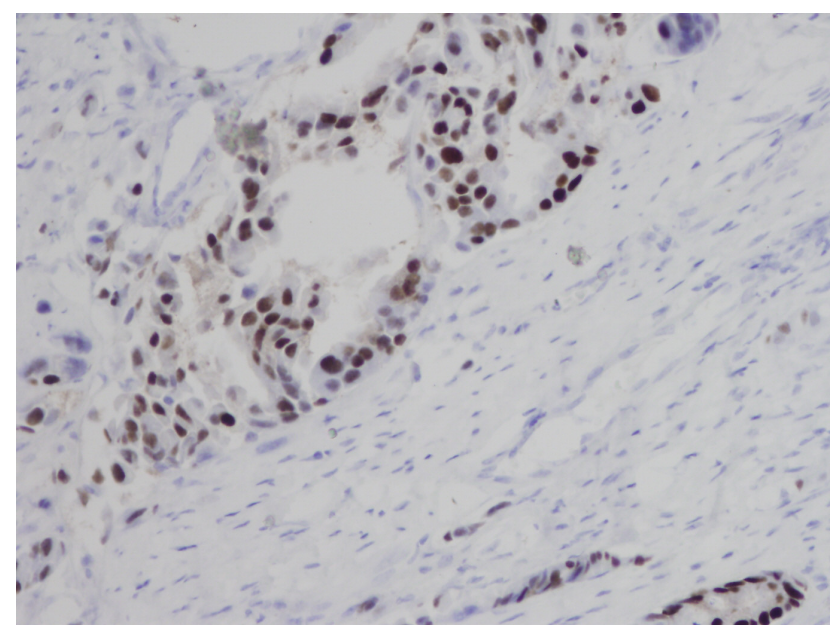

Fig. 2. Example of immunohistochemical examination of the tumor: Strong nuclear positivity of estrogen receptors in tumor cells (magnification 200x; monoclonal mouse anti-human estrogen receptor alfa; clone 1D; producer Dako).

ment after surgical release of agglutinated (by leptomeningeal infiltration) nerve roots of cauda equina.

\section{CONCLUSION}

To our knowledge, we report here the first case of successful surgical treatment of metastatic leptomeningeal infiltration of breast carcinoma. 


\section{ACKNOWLEDGEMENTS}

We would like to acknowledge support of grants from Czech Ministry of School and Education (MSM6198959216 and LC07017) and EEA/Norway Financial Mechanisms (CZ0099).

\section{REFERENCES}

1. Edelson RN, Deck MD, Posner JB. Intramedullary spinal cord metastases. Clinical and radiographic findings in nine cases. Neurology 1972; 22: 1222-1231.

2. Jellinger K, Kothbauer P, Sunder-Plassmann E, Weiss R. Intramedullary spinal cord metastases. J Neurol 1979; 220: 31-41.

3. Schiff D, O'Neill BP. Intramedullary spinal cord metastases: clinical features and treatment outcome. Neurology 1996; 47: 906-912.

4. Grem JL, Burgess J, Trump DL. Clinical features and natural history of intramedullary spinal cord metastasis. Cancer 1985; 56 : 2305-2314.

5. Findlay JM, Bernstein M, Vanderlinden RG, Resch L. Microsurgical resection of solitary intramedullary spinal cord metastases Neurosurgery 1987; 21: 911-915.

6. Gasser T, Sandalcioglu IE, El Hamalawi B, van de Nes JA, Stolke D, Wiedemayer H. Surgical treatment of intramedullary spinal cord metastases of systemic cancer: functional outcome and prognosis. J Neuro-Oncology 2005; 73: 163-168.

7. Connolly ES Jr, Winfree CHJ, McCormick PC, Cruz M, Stein BM. Intramedullary spinal cord metastasis: report of three cases and review of the literature. Surg Neurol 1996; 46:329-338.

8. Dunne JW, Harper CG, Pamphlett R. Intramedullary spinal cord metastases: a clinical and pathological study of nine cases. Q J Med 1986; 61: 1003-1020.

9. Potti A, Abdel-Raheem M, Levitt R, Schell DA, Mehdi SA Intramedullary spinal cord metastases (ISCM) and non-small cell lung carcinoma (NSCLC): clinical patterns, diagnosis and therapeutic considerations. Lung Cancer 2001; 31: 319-323.

10. Schijns OEMG, Kurt E, Wessels P, Luijckx GJ, Beuls EAM. Intramedullary spinal cord metastasis as a first manifestation of a renal cell carcinoma: report of a case and review of the literature. Clin Neurol Neurosurg 2000; 120: 249-254.

11. Stranjalis G, Torrens MJ. Successful removal of intramedullary spinal cord metastasis: case report. Br J Neurosurg 1993; 7: 193-195.

12. Lee SS, Kim MK, Sym SJ, Kim SW, Kim WK, Kim S-B, Ahn J-H Intramedullary spinal cord metastases: a single-institution experience. J Neurooncol 2007; 84: 85-89.

13. Sutter B, Arthur A, Laurent J, Chadduck J, Friehs G, Clarici G, Pendl G. Treatment options and time course for intramedullary spinal cord metastasis. Report of three cases and review of the literature. Neurosurgical Focus 1998; 4 (5): e3.

14. Dam-Hieu P, Seizeur R, Mineo JF, Metges JP, Meriot P, Simon H. Retrospective study of 19 patients with intramedullary spinal cord metastasis. Clin Neurol Neurosurg 2009; 111(1): 10-17. 